\title{
Comparison of genetic services with and without genetic registers: knowledge, adjustment, and attitudes about genetic counselling among probands referred to three genetic clinics
}

\author{
C Wright, L Kerzin-Storrar, P R Williamson, A Fryer, A Niindou, O Quarrell, D Donnai, \\ D Craufurd
}

See end of article for authors' affiliations

Correspondence to: Ms L Kerzin-Storrar, Academic Group of Medical Genetics and Regional Genetic Service, St Mary's Hospital,

Hathersage Road,

Manchester M13 $\mathrm{OJH}, \mathrm{UK}$; Lauren.Kerzin-Storrar@cmmc. nhs.uk

\begin{abstract}
Genetic register services incorporating long term follow up and a proactive approach to at risk subjects have been recommended as a way of improving access to genetic counselling for families with dominant or $\mathrm{X}$ linked genetic disorders and chromosome translocations. The aims of the present study were to evaluate the psychosocial benefits and drawbacks of long term family contact, and to evaluate the attitudes of probands and their general practitioners towards proactive genetic counselling. We interviewed 192 people referred to three regional genetic clinics because of a family history of Duchenne or Becker muscular dystrophy, myotonic dystrophy, or chromosome translocations, and 43 of the referring GPs. Probands attending the centre using a genetic register approach were compared with those from the two centres offering the standard clinical genetic service. A very high proportion of probands in both groups were well informed about the genetic risks to themselves and their children, were satisfied with the service they had received from their local genetic clinic, and felt adequately prepared to discuss the family illness with their children. The register probands expressed approval of the ongoing contact and open access provided by the register service. Asked whether previously unaware relatives should be informed of their at risk status, 98\% (188/192) said it was acceptable for this information to be disclosed by a family member, while three quarters of the probands (149/192) and just over half the GPs (27/43) thought it acceptable for the genetic service to approach them; a similar proportion of both GPs and probands also found it acceptable for GPs to do so. More than half the probands $(107 / 190)$ thought it was the family's responsibility to pass on genetic risk information, but $43 \%$ said that either the genetic service or the GP should be responsible for this. The findings show that the genetic register approach incorporating long term follow up and a proactive approach to genetic counselling is highly acceptable to the families concerned, and although the register and non-register probands did not differ significantly on any of the main outcome measures used in this relatively short term study, it may be that the continuing contact associated with the register approach offers long term benefits, especially for those genetic conditions where medical surveillance may have an impact on the prognosis.
\end{abstract}

G enetic counselling services are usually reactive, responding to the referral of a person or nuclear family affected by, or at risk of, a genetic disorder. The referral is generated either by the clinician caring for the affected person, or by an at risk relative who is aware of the family history and brings this to the attention of their doctor. This usually results in a genetic counselling episode which typically may involve one to three direct contacts with the service over a period of months. This pattern of service delivery does not address the potential genetic counselling needs over a lifetime, nor the needs of a large number of high risk relatives who have never been referred, but are known to exist because they have been identified on the pedigrees of referred probands. The geneticist or counsellor may indicate to the proband that the service is available to their relatives, either at the consultation or in the summary letter, but this is not necessarily routine and varies between practitioners. An alternative approach is that of a regional genetic family register service where genetic counselling is offered proactively to relatives at significant risk, and long term family contact is maintained. The proband is pivotal in the proactive approach as their permission to contact relatives is sought, and they are encouraged to discuss this with their relatives, before a letter offering a genetic appointment is sent. Where a proband is unable to discuss this with a relative, but gives consent that contact be made, this is first done through the relative's general practitioner (without disclosing the specific details of the genetic condition). This approach was recommended by a working party of the Clinical Genetics Society in 1978, ${ }^{1}$ and continued calls for development of these services have been made, ${ }^{2-4}$ but there has been little research into the effectiveness and acceptability of the genetic register approach.

The North West Regional Genetic Family Register service in Manchester allows for systematic follow up of probands and proactive genetic counselling for relatives, for 11 genetic conditions. $^{6-8}$ Family files are reviewed in detail by a genetic counsellor annually, follow up contact is offered, and the need for updated testing or screening is assessed. The systematic annual review of files also allows for a review of progress with contacting relatives, which may often involve recontacting probands or other family members, with the aim of ensuring that all at risk relatives, or their parents when minors, have been offered genetic counselling. It is extremely unusual for probands explicitly to refuse disclosure to their relatives, and these rare situations are usually resolved through continuing discussion and contact between the service and proband. The Merseyside Regional Genetic Centre in Liverpool and the North Trent Regional Genetic Services in Sheffield do not have 
Table 1 Description of usual practice for each genetic centre included in the study

\begin{tabular}{|c|c|c|c|}
\hline & Manchester & Liverpool & Sheffield \\
\hline \multicolumn{4}{|l|}{ Initial episode } \\
\hline \multicolumn{4}{|l|}{ Pre-clinic contact } \\
\hline Clinic appointment & Yes & Yes & Yes \\
\hline Summary letter & & & \\
\hline $\begin{array}{l}\text { Post-clinic follow up } \\
\text { Offer of genetic counselling for relatives }\end{array}$ & Yes & Yes & Yes \\
\hline \multicolumn{4}{|l|}{ Long term follow up } \\
\hline \multicolumn{4}{|l|}{$\begin{array}{l}\text { Systematic annual review of register files } \\
\text { leading to: }\end{array}$} \\
\hline $\begin{array}{l}\text { (A) Offer of counselling and updating } \\
\text { probands of new developments }\end{array}$ & Yes & No & No \\
\hline (B) Review of progress with contacting relatives & Yes & No & No \\
\hline
\end{tabular}

a systematic register, but do make the offer of genetic counselling for relatives as part of the initial genetic counselling episode. Table 1 summarises the usual practice at these genetic centres; all take a similar approach to the initial genetic counselling episode, but differ in the provision of long term follow up of probands and ascertainment of relatives.

We report on a multicentre study comparing a genetic register approach with the traditional non-register approach to genetic counselling services. In this report we consider the benefits or drawbacks of long term family contact, using measures of knowledge, anxiety, preparedness, and satisfaction. We also report on attitudes of probands and their general practitioners towards proactive genetic counselling.

\section{METHODS}

\section{Study design}

The study consisted of three parts. Part A was a retrospective study of probands and relatives. Part B was a prospective study of pregnant women and their partners. Part C involved interviews with the general practitioners (GPs) of the register group probands. This paper presents data on the probands from part A of the study, while data on the relatives are presented in the accompanying paper in this issue. Further data relating to the psychosocial impact of these familial disorders and the communication of risk by families and professionals, as well as the results of parts $\mathrm{B}$ and $\mathrm{C}$, will be presented elsewhere.

Four conditions were included in the study: Duchenne and Becker muscular dystrophy (DMD and BMD, respectively), myotonic dystrophy (MD), and balanced chromosome translocations (BT). These were selected because they all have significant reproductive implications including the possibility of testing in pregnancy. Funding for the study was provided by the Research and Development Programme (Mother and Child Health) of the National Health Service Executive, and ethical approval for the study was obtained from the Local Research Ethics Committees in Manchester, Liverpool, and Sheffield.

\section{Selection of subjects}

Subjects referred for genetic counselling (probands) were selected if at the time of referral they had a high prior risk $(>10 \%)$ of becoming affected themselves, or of having an affected child, with one of the specified conditions. Probands were eligible for inclusion if they had been first seen by the genetic counselling service between 01/01/90 and 31/12/96, were aged between 18 and 55 years in December 1996, and were still living in the geographical catchment area of the original genetic centre. Probands referred before 1990 were excluded because the genetic services in Liverpool and Sheffield were organised differently before this date. Eligible probands were invited to participate by letter. Permission was also sought to approach the GPs of probands in Manchester, who were then contacted and asked to participate in part $C$ of the study.

\section{Data collection}

Data for probands were collected in face to face interviews, between July 1997 and May 1999, using a semi-structured questionnaire completed by the interviewer. The interviewer was an independent researcher who had not been involved in the provision of genetic counselling to subjects. A mixture of closed and open ended questions was asked, addressing issues such as knowledge of the condition, contact and satisfaction with the genetic service, preparedness for future reproductive decisions, and the impact of living with the genetic condition. Knowledge of genetic risk status was measured by two closed questions in which probands were asked to indicate their own risk of being a carrier/affected, and their risk of having an affected child, by choosing one of six specified categories: "certain", "high", "low", "uncertain", "no risk", and "don't know".

All but three interviews were conducted in the person's home. All interviews were tape recorded and then transcribed before analysis. Subjects were also sent two standardised questionnaires to complete before the interview: the StateTrait Anxiety Index ${ }^{9}$ and an adapted version of Lermans' Cancer Worry Scale. ${ }^{10}$

The GPs were sent a short postal questionnaire, which was followed up by a telephone interview using a semi-structured questionnaire. These interviews were also tape recorded and transcribed

\section{Analysis}

A decision was made before data collection that subjects from Liverpool and Sheffield should be grouped together, as it was considered that the service approach in these centres was sufficiently similar, and equally distinct from the Manchester approach. For binary outcomes the two groups were compared using Fisher's exact test. For continuous outcomes, where the assumption of normality seemed appropriate, a two sample $t$ test was used. Open questions were analysed using qualitative methods to identify themes and categories. ${ }^{11}$ Coding categories were agreed by two separate researchers. Some open questions were then entered on the database with the quantitative data and analysed in the same way.

\section{RESULTS}

\section{Response rates}

A total of 353 probands were eligible for inclusion, of whom $192(54 \%)$ were interviewed. There were 25 (7\%) subjects for whom we could not obtain a current address, 68 (19\%) who declined, 55 (16\%) who did not respond, and 13 (4\%) for whom we were unable to arrange a convenient interview time. Of the 78 GPs of register probands who were approached, 43 
Table 2 Characteristics of the 192 probands interviewed, comparing those from the centre operating a genetic register service with those from the other two centres

\begin{tabular}{|c|c|c|}
\hline & Manchester & $\begin{array}{l}\text { Liverpool// } \\
\text { Sheffield }\end{array}$ \\
\hline \multicolumn{3}{|l|}{ Condition and status } \\
\hline \multicolumn{3}{|l|}{ DMD } \\
\hline Affected & 0 & 0 \\
\hline Carrier & 8 & 10 \\
\hline At risk & 10 & 14 \\
\hline Total & $18(22 \%)$ & $24(22 \%)$ \\
\hline \multicolumn{3}{|l|}{ BMD } \\
\hline Affected & 5 & 2 \\
\hline Carrier & 3 & 2 \\
\hline At risk & 2 & 4 \\
\hline Total & $10(12 \%)$ & $8(7 \%)$ \\
\hline \multicolumn{3}{|l|}{ MD } \\
\hline Affected & 17 & 24 \\
\hline Carrier & 0 & 0 \\
\hline At risk & 2 & 2 \\
\hline Total & $19(23 \%)$ & $26(24 \%)$ \\
\hline \multicolumn{3}{|l|}{ BT } \\
\hline Affected & 0 & 0 \\
\hline Carrier & 35 & 52 \\
\hline At risk & 0 & 0 \\
\hline Total & $35(43 \%)$ & $52(47 \%)$ \\
\hline Sex: female & $57(70 \%)$ & $87(79 \%)$ \\
\hline $\begin{array}{l}\text { Age: mean (range) at interview } \\
(\mathrm{n}=191)\end{array}$ & $36(23-55)$ & $36(20-52)$ \\
\hline \multicolumn{3}{|l|}{ Marital status } \\
\hline Married/living together & $59(72 \%)$ & 87 (79\%) \\
\hline Not in a relationship & $15(18 \%)$ & $14(13 \%)$ \\
\hline $\begin{array}{l}\text { In a relationship but not living } \\
\text { together }\end{array}$ & $8(10 \%)$ & $9(8 \%)$ \\
\hline $\begin{array}{l}\text { Previous pregnancy (male and } \\
\text { female) }\end{array}$ & 67 (81\%) & 102 (91\%) \\
\hline \multicolumn{3}{|l|}{ Year first seen in genetic clinic } \\
\hline 1990 & $10(12 \%)$ & 15 (14\%) \\
\hline 1991 & $14(17 \%)$ & $17(15 \%)$ \\
\hline 1992 & 15 (18\%) & $13(12 \%)$ \\
\hline 1993 & $13(16 \%)$ & $18(16 \%)$ \\
\hline 1994 & $11(13 \%)$ & $17(15 \%)$ \\
\hline 1995 & $8(10 \%)$ & $24(22 \%)$ \\
\hline 1996 & $11(13 \%)$ & $6(5 \%)$ \\
\hline \multicolumn{3}{|l|}{$\begin{array}{l}\text { Highest educational qualification } \\
\text { obtained }\end{array}$} \\
\hline No qualifications & $19(23 \%)$ & $27(25 \%)$ \\
\hline $\begin{array}{l}\text { O level/CSE (achieved at age } \\
\text { 16) }\end{array}$ & $30(37 \%)$ & 37 (34\%) \\
\hline $\begin{array}{l}\text { A level (achieved at age } 18 \text {, } \\
\text { required for university entrance) }\end{array}$ & $3(4 \%)$ & $6(5 \%)$ \\
\hline Diploma & $10(12 \%)$ & $12(11 \%)$ \\
\hline Vocational & $6(7 \%)$ & $13(12 \%)$ \\
\hline Bachelors degree & $10(12 \%)$ & $11(10 \%)$ \\
\hline Masters degree & $2(2 \%)$ & $3(3 \%)$ \\
\hline $\mathrm{PhD}$ & $1(1 \%)$ & $1(1 \%)$ \\
\hline Other & $1(1 \%)$ & $0(0 \%)$ \\
\hline \multicolumn{3}{|l|}{$\begin{array}{l}\text { One or more living affected family } \\
\text { members }\end{array}$} \\
\hline BMD & $6(60 \%)$ & 8 (100\%) \\
\hline $\mathrm{DMD}$ & $15(83 \%)$ & 19 (79\%) \\
\hline$M D$ & 15 (79\%) & $24(92 \%)$ \\
\hline BT & 5 (14\%) & $11(21 \%)$ \\
\hline $\begin{array}{l}\text { More than one carrier (BT) in } \\
\text { family }\end{array}$ & 27 (77\%) & 39 (75\%) \\
\hline
\end{tabular}

(55\%) were interviewed. There were 17 (22\%) who declined, $10(13 \%)$ who did not respond, and eight (10\%) for whom we were unable to arrange a convenient interview time.

\section{Characteristics of probands}

There were no significant differences between probands who consented to take part and those who did not, with regard to condition, age, gender, or site. Of the probands interviewed there were no differences between the register and nonregister groups for condition, genetic status, age at interview, marital status, highest level of education, year first seen by the genetics service, or number of living family members affected. Probands in the non-register group were slightly more likely to be female and to have had at least one pregnancy (table 2).

\section{Knowledge about genetic risk}

More than three quarters of the probands in both groups were able to identify the correct genetic risk category, both for themselves (148/191, 77\%) and for their children (152/187, $81 \%$ ) (table 3 ); no difference was found between the groups. Probands were also asked whether they knew of any tests available in pregnancy relevant to their genetic condition. Answers scored as correct for DMD, BMD, and MD were those which named or at least described chorionic villus sampling (CVS) and amniocentesis, and for BT those which named or described amniocentesis and/or CVS. The groups did not differ with regard to knowledge of relevant prenatal tests, but overall this was lower $(93 / 192,48 \%)$ than knowledge about level of risk (table 3 ). However, of those planning or possibly planning more children, knowledge was better (38/64, 59\%).

\section{Impact and adjustment}

There were no differences between the groups in their mean scores for State Anxiety or the modified Worry Scale (table 3 ). The Register approach did not appear to alter the amount of anxiety and worry experienced by the probands in the register group.

Most probands in both groups (173/192, 90\%) said that they felt adequately prepared to make future reproductive decisions. In the small group of probands who were still undecided about whether to have further children, 10/24 (42\%) reported that they felt able to make a decision. Probands were also asked how confident they felt, on an increasing scale of 0-6, about their ability to cope with potential problems in a future pregnancy. Again there was no difference between the study groups, with few respondents committing themselves to feeling either very confident or not at all confident (table 3 ).

Of the probands with children, nearly all $(53 / 158,97 \%)$ had either discussed the genetic condition with their children or felt prepared enough to discuss it when their children were older. There was no difference between the groups in this respect (register 63/66, 95\%; non-register 90/92, 98\%) (table $3)$.

\section{Satisfaction with the service}

A high proportion of probands in both groups had found genetic counselling helpful in understanding and coming to terms with their genetic condition. There was no difference between the groups (register 66/76, 87\%; non-register 86/108, $80 \%$ ) in this respect. When asked in an open question why it had been helpful, 63\% referred to provision of information and/or support. About a fifth (21\%) were unable to give a specific reason for why they had found it useful.

When asked how satisfied they were with the service they had received (table 4), most probands in both groups reported being "very" or "quite" satisfied (register 79/82, 96\%; non-register $101 / 110,92 \%)$. Probands then responded to an open enquiry about what they felt had contributed to their degree of satisfaction with the service. Of the register probands who said they were "very satisfied" with the service, the most common reason given was related to the information they had received $(21 / 46,46 \%)$. They mentioned in particular information about the condition, its inheritance pattern, and clarity of information. The next most frequent reason given was the nature of the support they had received (17/46, 37\%). A fifth of the register group (9/46, 20\%) mentioned "keeping in contact" as a reason for satisfaction. Other reasons mentioned by fewer people included the attitude of the counsellor $(3 / 46,7 \%)$, prompt appointments $(3 / 46,7 \%)$, and a perception that they had tried to do everything to help $(3 / 46,7 \%)$. 
Table 3 Knowledge, adjustment, and preparedness of probands to cope with future problems and decisions related to their genetic condition: comparison of probands from the centre operating a genetic register service (Manchester) with those from the other two genetic centres

\begin{tabular}{|c|c|c|c|}
\hline & Manchester & $\begin{array}{l}\text { Liverpool/ } \\
\text { Sheffield }\end{array}$ & $\mathrm{p}$ value \\
\hline \multicolumn{4}{|l|}{ Knowledge } \\
\hline Correct risk for self $(n=191)$ & $65(80 \%)$ & $83(75 \%)$ & 0.43 \\
\hline Correct risk for children $(n=187)$ & $61(77 \%)$ & $91(84 \%)$ & 0.22 \\
\hline Identified prenatal test $(n=192)$ & $36(44 \%)$ & $57(52 \%)$ & 0.28 \\
\hline \multicolumn{4}{|l|}{ Lerman worry score: } \\
\hline Mean (SE) $(n=129)$ & $5.8(0.44)$ & $6.7(0.37)$ & 0.12 \\
\hline \multicolumn{4}{|l|}{ STAI state anxiety score: } \\
\hline Mean (SW) $(n=167)$ & $36.6(1.42)$ & $39.7(1.20)$ & 0.10 \\
\hline \multicolumn{4}{|l|}{ Would contact genetic centre under specified circumstances: } \\
\hline Pregnancy $(n=169)$ & $30(40 \%)$ & $28(30 \%)$ & 0.17 \\
\hline Change in symptoms $(n=145)$ & $17(25 \%)$ & $15(19 \%)$ & 0.12 \\
\hline Information ( $n=192)$ & $63(77 \%)$ & $69(63 \%)$ & 0.04 \\
\hline Emotional support ( $n=192)$ & $24(29 \%)$ & $17(15 \%)$ & 0.02 \\
\hline \multicolumn{4}{|l|}{ Feel adequately prepared to make reproductive decisions: } \\
\hline All probands $(n=192)$ & $75(91 \%)$ & $98(89 \%)$ & 0.59 \\
\hline Those planning more children $(n=40)$ & $16(89 \%)$ & $21(95 \%)$ & 0.92 \\
\hline Those not planning more children $(n=128)$ & $54(96 \%)$ & $72(100 \%)$ & 1.0 \\
\hline Undecided about more children $(n=24)$ & $5.0(63 \%)$ & $5(31 \%)$ & 0.15 \\
\hline \multicolumn{4}{|c|}{ Feel confident to cope with problems in any future pregnancy: } \\
\hline Those planning more children $(n=40)$ & 2.7 & 3.4 & 0.16 \\
\hline Undecided about more children $(n=24)$ & 3.6 & 3.3 & 0.65 \\
\hline $\begin{array}{l}\text { Have discussed/feel adequately prepared to discuss condition } \\
\text { with children }(n=158)\end{array}$ & $63(95 \%)$ & $90(98 \%)$ & 0.65 \\
\hline
\end{tabular}

Table 4 Level of satisfaction with the genetics service, comparing probands from the genetic register centre (Manchester) with those from the other two genetic centres

\begin{tabular}{lll}
\hline & Manchester & \multicolumn{1}{l}{$\begin{array}{l}\text { Liverpool/ } \\
\text { Sheffield }\end{array}$} \\
\hline Very satisfied & $46(56 \%)$ & $49(45 \%)$ \\
Quite satisfied & $33(40 \%)$ & $52(47 \%)$ \\
Not satisfied at all & $3(4 \%)$ & $9(8 \%)$ \\
\hline
\end{tabular}

Examples included: “Because everything I've asked they've tried to answer for me. They're very very helpful. They've sent me literature, the numbers of support groups and they've kept me up to date on the progress being made on the problem, the condition." [Manchester MD proband] "They've really kept in touch with me, it's made me feel if my wife does get pregnant, which we're hoping eventually she will, there is somebody I can speak to who can help us." [Manchester BT proband] "It's really keeping you updated on what's happening. Because I've had a baby it's not just ignoring the fact that, you know oh well she's had a baby and that's it. They still keep me informed and write to me once a year to let me know what's going on." [Manchester BT proband]

Of the Liverpool/Sheffield probands who reported being "very satisfied" with the service they had received, the two most frequent reasons given were the same as for the register group: the quality of the information $(30 / 49,61 \%)$ and the support $(12 / 49,24 \%)$ they had received. The only difference between the two groups was that the non-register probands did not give "keeping in contact" as a reason for satisfaction, which was not surprising given that these services do not offer long term follow up. Examples of responses from non-register probands include: "Because any questions I've had about genetics they've answered them as simply as possible. Because I know genetics is very difficult to understand and they've put it in simplest forms, 'cos when they start with these long words I'm lost." [Sheffield DMD proband]. "Well because whenever we've been there they've all been friendly and understanding, they explained everything very clearly, they gave us a lot of information really." [Liverpool DMD proband]

Only a few people said they were "not satisfied at all" (register $3 / 82,4 \%$; non-register $9 / 110,8 \%$ ). Reasons for dissatisfaction included "no follow up", "not enough information", and a perceived "lack of support". Just under a third of each study group mentioned some way in which they thought the service could be improved (register 25/82, 30\%; non-register 34/110, $31 \%)$. The most frequently given suggestions for improvement were "more information" (register 10/25, 40\%; non-register $8 / 34,24 \%$ ) and "more follow up" (register 2/25, 8\%; non-register $13 / 34,38 \%$ ).

Register probands were asked specific questions about their views of the Genetic Family Register service. Most probands $(74 / 82,90 \%)$ agreed with the concept of the register, and the most frequently mentioned reason in support of the register was the associated ongoing "open door" access to the service $(49 / 82,66 \%)$. This included comments related to maintaining contact, as well as ensuring that the future needs of children are not forgotten. Other reasons given included being kept up to date with medical advances, contributing to research data, facilitating earlier diagnosis, and monitoring progression of symptoms. "It's nice to know you've not been forgotten because obviously I'm going to come up to some problems when the boys get older. Yeah it's just that they're there and I know they're there, it's just reassurance." [Manchester BT proband] "Well if you get one [letter] right at the beginning ...it might be a few years and then you've lost it. So at least you know that they are actually keeping in contact with you, so they are concerned, you're not just another name." [Manchester BMD proband] The seven people $(7 / 82,9 \%)$ who did not think the register was a useful approach stated that the service was not necessary or relevant to their personal situation.

A high proportion of probands (140/192, 73\%) from both study groups recalled receiving a summary letter, and most of these $(120 / 140,86 \%)$ had found the letter either "very useful" or "quite useful". However, fewer probands from the non-register group had shown the letter to other family members (register 46/60, 77\%; non-register 47/80, 59\%) while twice 
Table 5 Probands' perception regarding frequency of contact with the genetics department

\begin{tabular}{lcc}
\hline & Manchester & $\begin{array}{c}\text { Liverpool/ } \\
\text { Sheffield }\end{array}$ \\
\hline Annual contact & $26(32 \%)$ & $2(2 \%)$ \\
Several contacts & $23(28 \%)$ & $40(36 \%)$ \\
One follow up only & $13(16 \%)$ & $22(20 \%)$ \\
No follow up & $20(24 \%)$ & $45(41 \%)$ \\
Missing data & 0 & $1(1 \%)$ \\
\hline
\end{tabular}

as many non-register probands had not shown their letter to anyone (register 8/60, 13\%; non-register 26/80, 33\%).

\section{Continuing contact with the genetics service}

Of the register probands, $41 \%$ (34/82) said they were still in contact with the genetic department compared with only $14 \%$ (15/110) of non-register probands. When asked an open question about what contact they had had since their initial consultation with the genetics service, responses related to both frequency of contact (table 5) and nature of contact. As might be expected with a register approach, more probands in the register group said they were still in contact with the department, more mentioned having annual contact (register $26 / 82,32 \%$; non-register $2 / 110,2 \%$ ), and fewer felt that they had had no follow up (register 20/82, 24\%; non-register $45 / 110,41 \%)$.

Probands were asked who they would contact first (genetics service, GP, other, no-one, or not sure) under specific circumstances such as pregnancy, information about the genetic condition, emotional support, or a change in symptoms in themselves or an affected relative. Significantly more register probands said they would contact the service for emotional support than in the non-register group (register 24/82, 29\%; non-register 17/110, 15\%). The GP was most frequently mentioned as the person who would be contacted first in the event of pregnancy $(97 / 169,57 \%)$. For a change in symptoms in themselves or an affected relative, 37\% (56/145) said they would contact the GP first, while 29\% (42/145) would contact another specialist. Eighty-one subjects (42\%) reported that they would turn to non-professionals (family and friends) for emotional support.

\section{Acceptability of proactive approach to relatives}

Probands in both groups were asked if they thought it was acceptable for other family members to be informed about their genetic risk by the proband or a family member, the GP, or the genetics service (table 6). Only one proband thought it unacceptable for any of these people to inform an at risk relative, while $98 \%$ (188/192) thought it acceptable coming from the proband, $78 \%$ (149/192) from the genetics service, and $68 \%$ (130/192) from the GP. There were no differences between the two study groups in this respect. GPs were asked the same question, with similar results; $80 \%$ (37/43) of GPs thought it was acceptable for the proband to inform relatives, 63\% (27/43) for the genetics service, and 70\% (30/43) for the GP to inform.

Respondents were then asked who should have the main responsibility for contacting relatives, choosing from a list of options (table 6). Just over half $(107 / 189,57 \%)$ thought it was the responsibility of the family, almost a quarter (44/189, 23\%) thought it was the genetic department's responsibility, and under $10 \%(17 / 189,9 \%)$ saw it as the GP's responsibility. The GPs interviewed were also asked an open question about whose responsibility it should be to contact relatives. Fewer GPs than probands felt that the patients themselves should be responsible for contacting relatives $(8 / 41,20 \%)$, and a higher proportion $(16 / 41,39 \%)$ thought that the genetic department
Table 6 Opinions of probands concerning the acceptability of informing other family members about their at risk status and whose responsibility it should be to do so

\begin{tabular}{lc}
\hline & All probands \\
\hline Acceptability of relatives being informed by $(\mathrm{n}=190)$ \\
Self or another family member & $188(98 \%)$ \\
Genetic service & $149(78 \%)$ \\
GP & $130(68 \%)$ \\
Not acceptable at all & $1(0.5 \%)$ \\
Responsibility for informing relatives $(\mathrm{n}=189)$ & $107(57 \%)$ \\
Self or another family member & $44(23 \%)$ \\
Genetic service & $17(9 \%)$ \\
GP & $14(7 \%)$ \\
Joint (self and genetics) & $8(4 \%)$ \\
Don't know & \\
\hline
\end{tabular}

should have the responsibility. Only a few GPs (4/41, 10\%) thought that they should be responsible, and a similar number $(5 / 41,12 \%)$ thought that they should have a joint responsibility with the genetic department.

\section{DISCUSSION}

\section{Knowledge}

A high proportion of subjects in both study groups had an accurate knowledge of their genetic risk and the risk to their children. This was consistent with other studies which have investigated recall of knowledge following genetic counselling. ${ }^{12-14}$ It is therefore of interest that subjects described provision of information as a key reason for their high level of satisfaction with genetic counselling (see below). Surprisingly, only about $50 \%$ of subjects in both groups were aware of relevant prenatal tests, although the rate was somewhat higher in those subjects where reproduction was still an issue. Receiving annual follow up through the genetic register service in Manchester did not improve the basic knowledge parameters (level of risk and awareness of appropriate prenatal tests) measured in this study.

\section{Satisfaction}

Nearly all the subjects in both study groups reported satisfaction with the genetic counselling service. However, interpretation of satisfaction with genetic counselling is fraught with difficulty, because measures of satisfaction may be influenced by the implications of the information imparted to a particular person (for example, whether tests show a high level of risk, etc). ${ }^{15}$ It is therefore interesting that satisfaction was so high in the present study, where nearly all probands had a significant level of genetic risk and were often living with the effects of the genetic condition in themselves or a close relative. It is possible that subjects who agreed to participate may have felt an obligation to report a positive view of the service they had received, even though the research interviewer made it clear that she was not a member of the clinical team; however, satisfaction was also explored through asking subjects whether they had found genetic counselling "helpful in understanding and coming to terms with the genetic condition", and almost as many subjects confirmed that genetic counselling had been useful in this way. Subjects in both groups reported that information provision and support were the main reasons for satisfaction with the service, and a substantial proportion of those in the genetic register group also referred to the continuing contact as having contributed to their high level of satisfaction. This is consistent with a recent survey of genetic counsellors and their clients from North America, which found that clients appreciated the provision of clear, comprehensive information in an unhurried manner 
and valued the counsellor as a continuing resource for both information and support. ${ }^{16}$

Writing personal summary letters following genetic clinic consultations is now standard practice in many centres. Most of the probands in both study groups thought that the written summary letters were a useful adjunct to genetic counselling, but those in the genetic register group were more likely to have shown their letter to other people including family members. It may be that probands in the register group were more likely to extend the service's explicit offer of genetic counselling to their relatives, and made use of the summary letter when doing so.

\section{Impact and adjustment}

Probands receiving regular follow up with the genetic department through the register service in Manchester did not exhibit higher (or lower) levels of state anxiety as measured by the STAI. In view of the possibility that a general measure of anxiety such as the STAI might prove insensitive to specific anxieties about respondents' genetic risk status, we also administered a modified version of the Lerman Cancer Worry Scale, adapted to measure the impact of intrusive thoughts, worries, and concerns about "the genetic condition in your family"; again, there was no difference between the mean scores of the register and non-register groups. In a recent survey of North American genetic service providers (GSPs) (clinical geneticists, PhD geneticists, and genetic counsellors), $82 \%$ of GSPs cited the possibility of causing anxiety and stress as a potential disadvantage of re-contacting former patients to update them about current research developments. ${ }^{17}$ It is therefore reassuring that the register group in the present study did not exhibit higher levels of worry or concern, given the possibility that annual letters reminding them of their high risk genetic status might have had the effect of undermining defence mechanisms such as denial and thus increasing psychological distress. On the other hand, our findings do not support our alternative hypothesis either, that the regular contact and follow up provided by the register service might exert a beneficial effect on anxiety levels.

As expected, probands seen for their initial consultation at the centre providing a genetic register service reported more follow up than those from the non-register centres, and it is necessary to ask whether the benefits justify the resources required to maintain the system of regular review and follow up described here. Although the register and non-register groups did not differ significantly on any of the main outcome measures of knowledge, satisfaction, or emotional adjustment used in this study, it is noteworthy that nearly two-thirds of the register probands described the value of the continuing "open door" access which the register service provides. More of the register probands than the non-register group said they would contact the genetic service if they needed additional information, and twice as many register probands said they would approach the genetic service first if in need of emotional support. However, register probands were not significantly more likely to contact the genetic service first in the event of a pregnancy or a change in their own symptoms or those of a relative, suggesting that continuing genetic register follow up may be valued more for supportive rather than practical help, at least for conditions with mainly reproductive implications.

The practical benefits of long term review and follow up by the genetic register service for families at risk of hereditary cancers, and disorders such as adult polycystic kidney disease or neurofibromatosis where regular screening allows early detection and prevention, were not the focus of this study. The less tangible benefits concerned with knowledge, emotional adjustment, and support as described above are more difficult to assess, but it is worth noting that the probands in the present study were interviewed a relatively short period after their initial genetic counselling contact; the longest interval was seven years, and $40 \%$ of the sample were interviewed less than five years after the initial genetic contact. It is possible that differences would have emerged between the register and non-register probands in terms of accurate recall of information, and the degree to which this information was rendered out of date by more recent scientific advances, had it been possible to study a cohort with a longer interval between initial genetic counselling referral and the study interview.

\section{Communicating genetic risk information to relatives}

Many subjects seen in genetic clinics because of a family history of dominant or $\mathrm{X}$ linked disorders or chromosome rearrangements have relatives who are at risk of the condition themselves, or of having affected children. Clinical genetic practice therefore incurs at least some responsibility for informing such relatives of their at risk status, and this was one of the original reasons put forward for the establishment of genetic registers. ${ }^{1}$ However, the right of family members to this information has to be balanced against their right to "blissful ignorance"18 and the possibility that unsolicited approaches to relatives may cause anxiety and distress, creating a potential dilemma for the genetic counsellor. A proposed international code of ethics for medical genetics ${ }^{19}$ suggested that family members have a moral obligation to share genetic information with each other, and few would disagree with the view of Wilcke ${ }^{18}$ that clinicians also have an obligation to inform relatives who are at risk of a life threatening inherited disorder such as $\alpha_{1}$-antitrypsin deficiency where preventative measures such as changes in lifestyle can significantly affect the outcome. However, there is no clear consensus about the ethical basis for unsolicited disclosure of genetic information to relatives in circumstances where the risk is not to the health of the relatives themselves, but of having a child affected with the family disorder.

All but one of the 192 probands in the present study found it acceptable that relatives should be informed of their at risk status in one way or another; $98 \%$ of the probands thought it acceptable for this information to be disclosed by a family member, while three quarters of the probands and just over half the GPs thought it acceptable for someone from the clinical genetic service to inform relatives of their genetic risk. These findings are consistent with a large Danish survey of affected and at risk subjects with a family history of $\alpha_{1}$-antitrypsin deficiency of whom less than $10 \%$ objected to the suggestion that affected subjects should disclose the identities of their relatives (children, sibs, parents) to their physicians to enable them to offer testing. ${ }^{20}$ The responses of participants in the Danish study and the UK study presented here suggest that those with personal experience of the family illness favour disclosure of genetic risk information and respect for their relatives' autonomy rather than their right to remain ignorant, at least for disorders where the knowledge of being at risk will empower the relatives to take some sort of preventative action if they so wish.

While there was striking unanimity among respondents in the present study about the acceptability of informing relatives, there was no such consensus on the question of whose responsibility it was to do so. In their 1993 report on ethical issues relating to genetic screening, the Nuffield Council on Bioethics stated that the primary responsibility for communicating genetic information to a family member or third party lies with the individual person and not with the doctor. ${ }^{21}$ This issue was also addressed by the Medical Ethics Committee of the British Medical Association in a report entitled "Human Genetics: Choice and Responsibility". ${ }^{22}$ They suggested that patients should be strongly encouraged to raise the issue with family members; however, in those cases where a person is unwilling or unable to do so but gives consent for the information to be shared, the genetic centre should 
approach the relatives through their GPs. We were therefore surprised to find that only $57 \%$ of probands considered it their responsibility to inform relatives. Probands described difficulties in speaking with family members, including a lack of confidence in their ability adequately to explain the genetic aspects, estrangement or discord in the family, and a feeling that the presence of the genetic condition was in itself a large enough burden to carry. Interestingly, even fewer GPs thought that the probands should shoulder this responsibility, with half the GPs expecting the genetic service to take it on, either alone or in partnership with the GP. If the views of probands and GPs in the present study were generally accepted, it would have important implications for service provision, especially for those services who do not operate a genetic register system at present.

\section{CONCLUSION}

The register probands did not differ significantly from the non-register probands on any of the main outcome measures used in the present study, although it was clear that many valued the continuing contact and open door access provided by the genetic register approach. This study did not address the possibility of long term benefits from maintaining regular contact over many years, since the probands included here had been followed for a period not exceeding seven years; neither did we investigate the advantages of this approach to service delivery for conditions where long term medical surveillance may influence the prognosis and survival of affected subjects. Furthermore, this study did not attempt to assess the comparative efficiency of a register and non-register approach to service provision with respect to staff and other resources.

The most controversial difference between the genetic register approach to service provision and the more traditional method of organising genetic services concerns the policy of systematically offering genetic counselling to at risk family members who may otherwise be unaware that they are at risk. Almost all the probands in the present study approved of proactively approaching at risk relatives, a finding consistent with the only other published study to have looked in detail at this question, and a surprisingly large proportion of respondents took the view that clinical geneticists should assume at least some of the responsibility for this. These findings should help to inform discussions about the organisation and responsibilities of genetic service providers.

\section{ACKNOWLEDGEMENTS}

We are grateful to Patricia Sloper for help and advice in the design of the study; to Wendy Waterson, Johannah Ayres, and Isobel Atkinson for secretarial assistance; and to our colleagues in the three centres, especially Helen Kingston, Jill Clayton-Smith, Nicola Crawford, Ian Ellis, Jacqueline Flynn, and Rodney Harris. We particularly wish to acknowledge the families who participated and spoke so openly about their views and experiences. This work was supported by a grant from the NHS National Research and Development programme (Mother and Child Health), and the NHS Executive South East.

\section{Authors' affiliations}

C Wright, L Kerzin-Storrar, A Niindou, D Donnai, D Craufurd, Academic Group of Medical Genetics and Regional Genetic Service, Manchester, UK

P R Williamson, Department of Mathematical Sciences, University of Liverpool, Liverpool, UK

A Fryer, Department of Clinical Genetics, Alder Hey Hospital, Liverpool, UK

O Quarrell, Department of Clinical Genetics, Sheffield Children's Hospital, Sheffield, UK

\section{REFERENCES}

1 Dean JCS, Fitzpatrick DR, Farndon PA, Kingston H, Cusine D. Genetic registers in clinical practice: a survey of UK clinical geneticists'. J Med Genet 2000;37:636-40.

2 Emery AEH, Brough C, Crawfurd M, Harper P, Harris R, Oakshott G. A report on genetic registers. J Med Genet 1978;15:435-42.

3 Read AP, Kerzin-Storrar L, Mountford RC, Elles RG, Harris R. A register based system for gene tracking in Duchenne muscular dystrophy. J Med Genet 1986;23:581-6.

4 Burn J, Chapman P, Delhanty J, Wood C, Lalloo F, Cachon-Gonzalez MB, Tsioupra K, Church W, Rhodes M, Gunn A. The UK Northern Region genetic register for familial adenomatous polyposis coli: use of age of onset, congenital hypertrophy of the retinal pigment epithelium, and DNA markers in risk calculations. J Med Genet 1991;28:289-96.

5 Bradshaw N, Holloway S, Kerzin-Storrar L, Macleod. A Genetic Family Register as a model of proactive genetic counselling. J Med Genet 1998;35(suppl 1):559.

6 Kerzin-Storrar L, Khan AA, Watters EA, Kingston H, Craufurd D, Harris R. A Regional Genetic Family Register: opportunity for active - rather than reactive - genetic counselling. Am J Hum Genet Suppl 1991;49:42.

7 Evans DGR, Maher ER, Macleod R. Update of genetic testing for cance predisposition. J Med Genet 1997;34:746-8.

8 Benjamin CM, Colley A, Donnai D, Kingston H, Harris R, Kerzin-Storrar L. Neurofibromatosis type 1 (NFI): knowledge, experience and reproductive decisions of affected individuals and families. J Med Genet 1993;30:567-74.

9 Spielberger CD, Gorsuch RL, Lushene RF. Manual for the State-Trait Anxiety Inventory. Palo Alto: Consulting Psychologists Press, 1970.

10 Lerman C, Kash K, Stefanek M. Younger women at increased risk for breast cancer: perceived risk, psychological well-being and surveillance behaviour. Monogr Natl Cancer Inst 1994;16:171-6.

11 Miles MB, Huberman AM. Qualitative data analysis. London: Sage, 1984.

12 Hodgkinson KA, Kerzin-Storrar L, Watters EA, Harris R. Adult polycystic kidney disease: knowledge, experience, and attitudes to prenatal diagnosis. J Med Genet 1990;27:552-8.

13 Somer M, Mustonen H, Norio R. Evaluation of genetic counselling: recall of information, post-counselling reproduction, and attitude of the counselees. Clin Genet 1988;34:352-65

14 Faulkner CL, Kingston HM. Knowledge, views, and experience of 25 women with myotonic dystrophy. J Med Genet 1998;35:1020-5.

15 Shiloh S, Avdor O, Goodman RM. Satisfaction with genetic counselling: dimensions and measurement. J Med Genet 1990;27:522-9.

16 Bernhardt BA, Biesecker EB, Mastromarino CL. Goals, benefits, and outcomes of genetic counselling: client and genetic counsellor assessment. Am J Med Genet 2000;94:189-97.

17 Fitzpatrick JL, Hahn C, Costa T. The duty to re-contact: attitudes of genetic service for providers. Am J Hum Genet 1999;64:852-60.

18 Wilcke JTR. Late onset genetic disease: where ignorance is bliss, is it folly to inform relatives? BM 1998;317:744-7.

19 Wertz DC, Fletcher JC. Proposed: an international code of ethics for medical genetics. Clin Genet 1993;44:37-43

20 Wilcke JTR, Seersholm N, Kok-Jensen A, et al. Transmitting genetic risk information in families' attitudes about disclosing the identity of relatives. Am J Hum Genet 1999;65:902-9.

21 Nuffield Council of Bioethics. Genetic screening. London: Nuffield Council of Bioethics, 1993.

22 British Medical Association. Human genetics: choice and responsibility. Oxford: Oxford University Press, 1998. 